Supplement of Atmos. Chem. Phys. Discuss., 15, 32831-32887, 2015

http://www.atmos-chem-phys-discuss.net/15/32831/2015/

doi:10.5194/acpd-15-32831-2015-supplement

(C) Author(s) 2015. CC Attribution 3.0 License.

(c) (i)

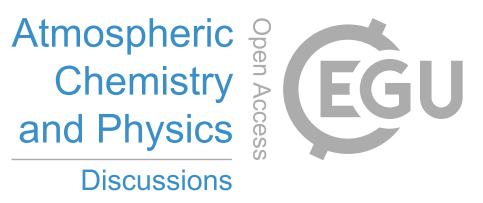

Supplement of

\title{
Profiling of aerosol microphysical properties at several EARLINET/AERONET sites during July 2012 ChArMEx/EMEP campaign
}

M. J. Granados-Muñoz et al.

Correspondence to: M. J. Granados-Muñoz (mjgranados@ugr.es)

The copyright of individual parts of the supplement might differ from the CC-BY 3.0 licence. 
Supplementary material:

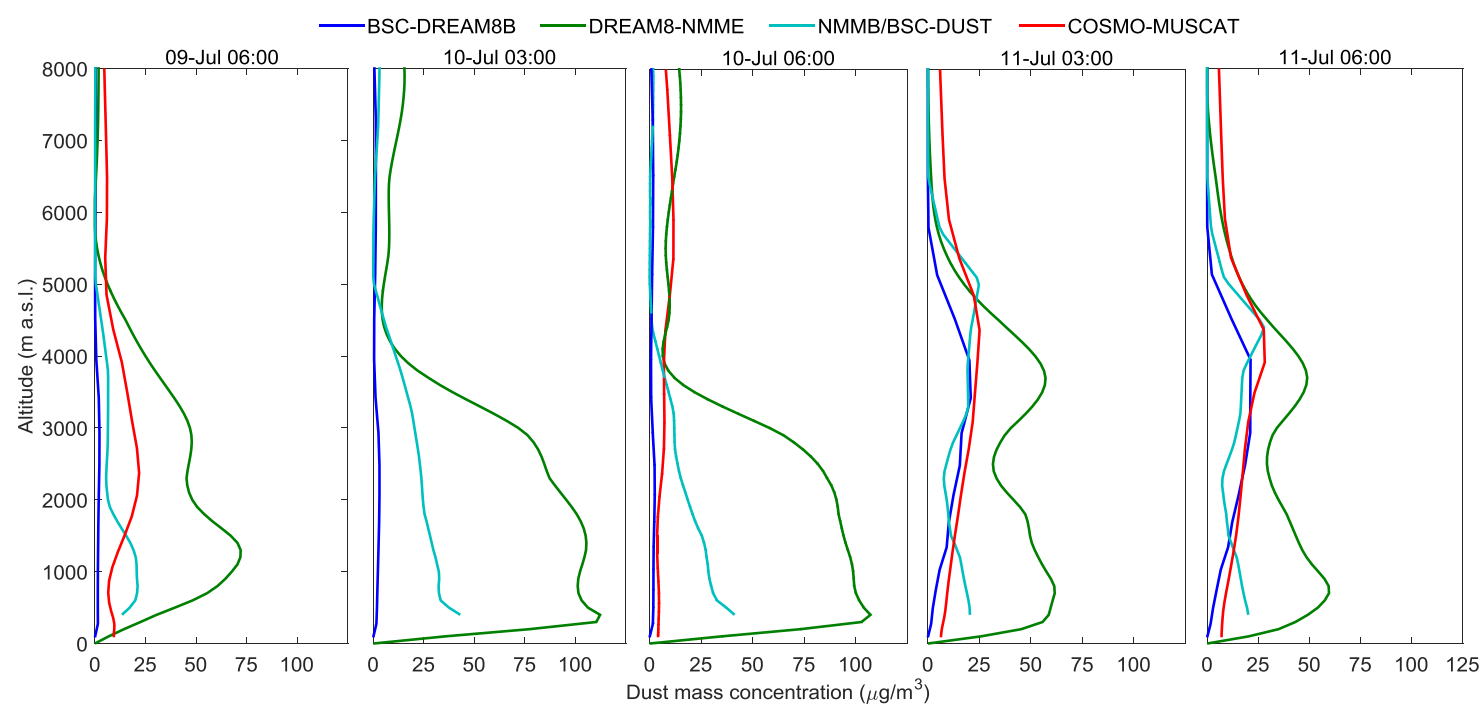

Figure S1. Dust mass concentration profiles forecast by BSC-DREAM8b-v2, DREAM8-NMME, NMMB/BSC-Dust and COSMO-MUSCAT at Athens in the period 9 July 2012-11 July 2012. Only those data coincident with AERONET inversion retrievals ( \pm 3 hours) has been presented here. 


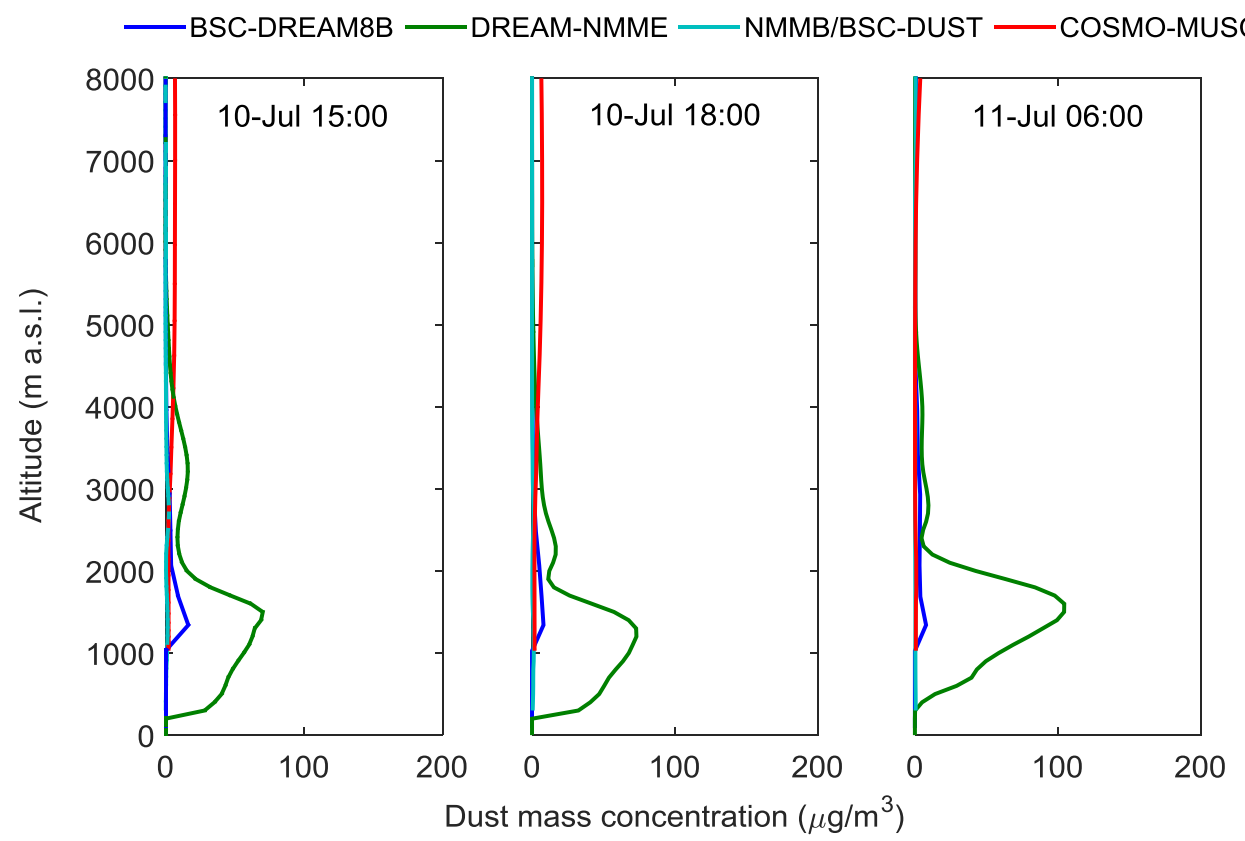

Figure S2. Dust mass concentration profiles forecast by BSC-DREAM8b-v2, DREAM8-NMME, DREAMABOL and NMMB/BSC-Dust at Barcelona in the period 9 July 2012-11 July 2012. Only those data coincident with AERONET inversion retrievals ( \pm 3 hours) has been presented here. 


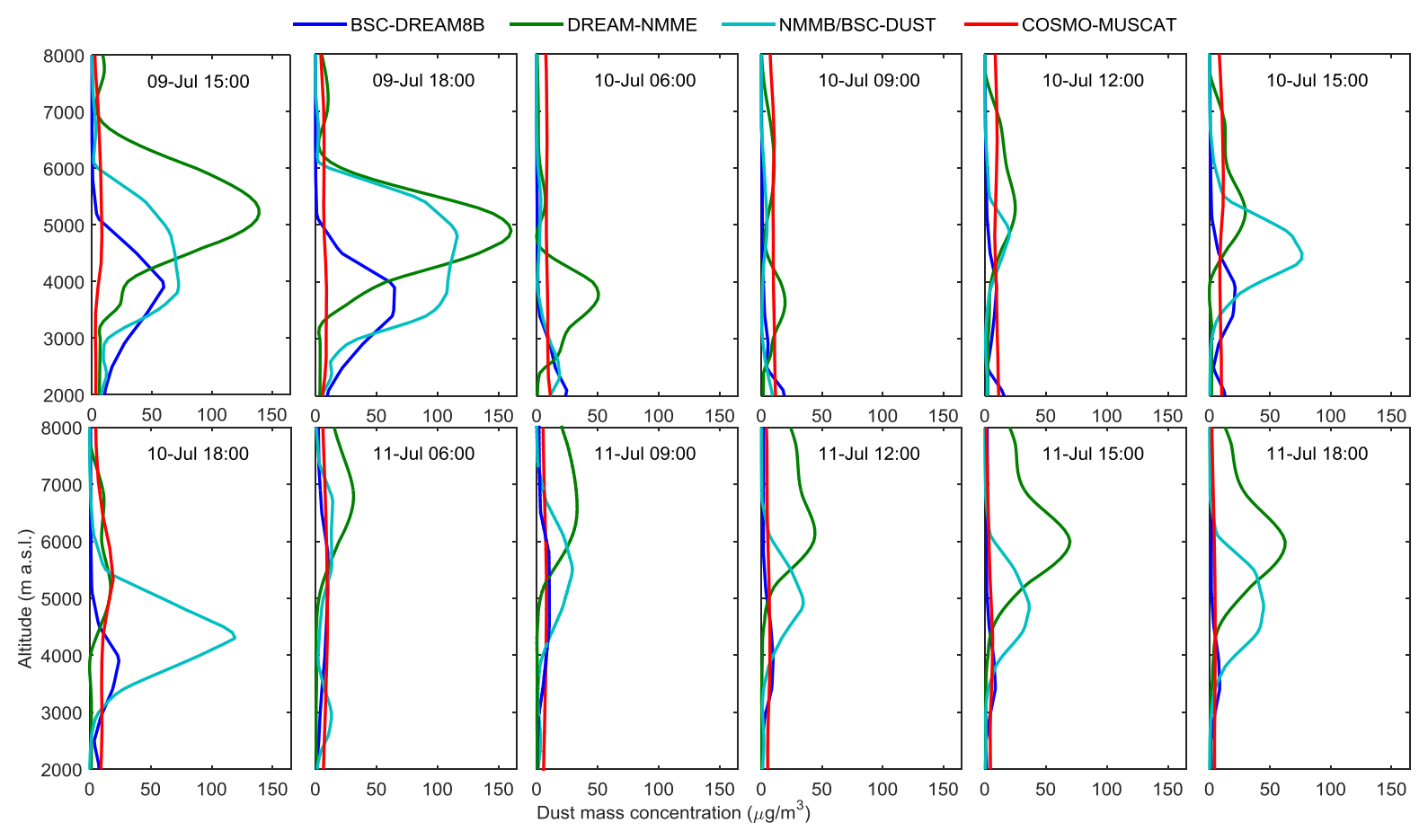

Figure S3. Dust mass concentration profiles forecast by BSC-DREAM8b-v2, DREAM8-NMME, NMMB/BSC-Dust and COSMO-MUSCAT at Bucharest in the period 9 July 2012-11 July 2012. Only those data coincident with AERONET inversion retrievals ( \pm 3 hours) has been presented here. 


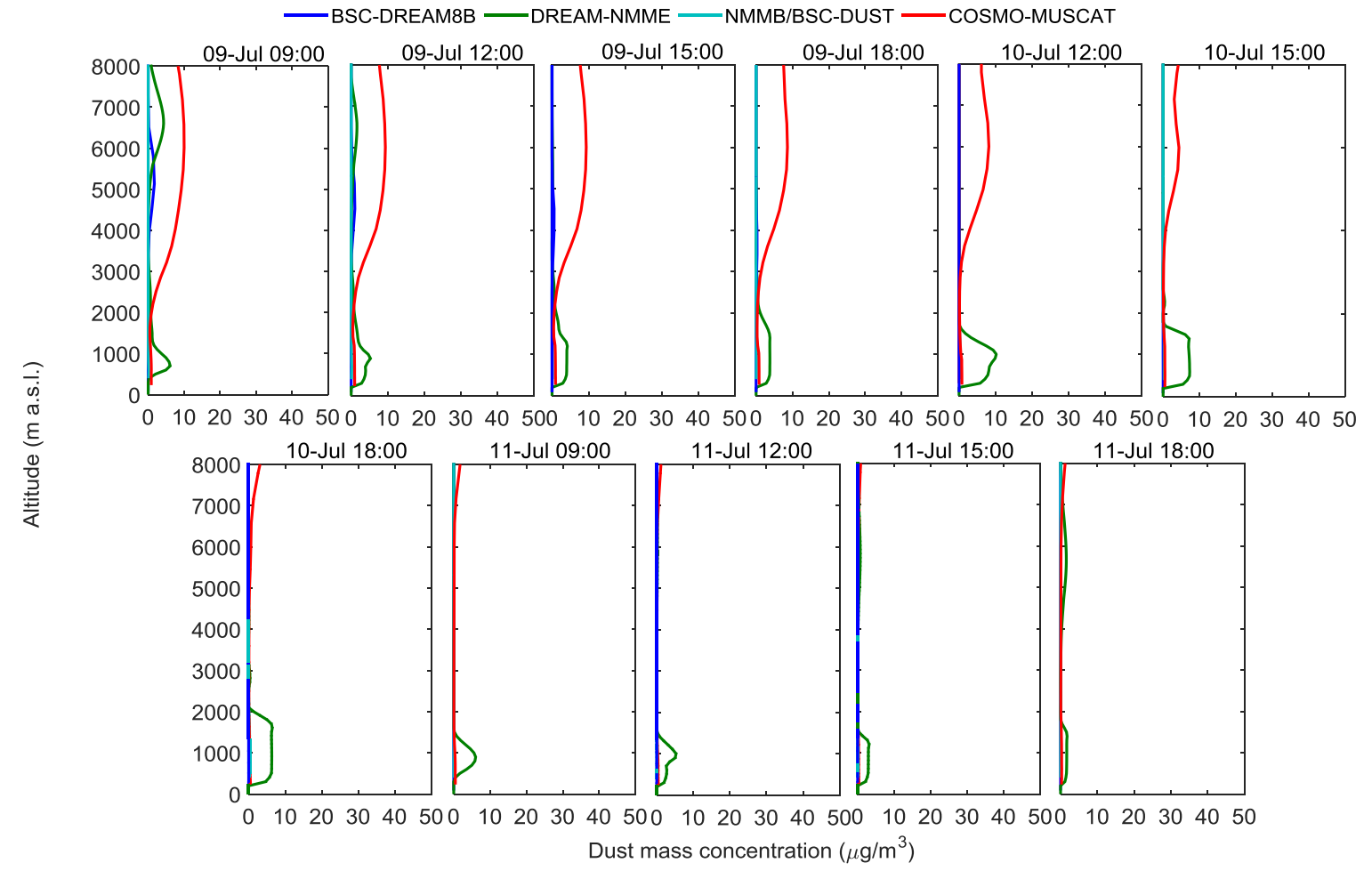

Figure S4. Dust mass concentration profiles forecast by BSC-DREAM8b-v2, DREAM8-NMME, NMMB/BSC-Dust and COSMO-MUSCAT at Évora in the period 9 July 2012-11 July 2012. Only those data coincident with AERONET inversion retrievals ( \pm 3 hours) has been presented here. 